\title{
The Southern Hemisphere and equatorial region ionization response for a 22 September 1999 severe magnetic storm
}

\author{
E. Yizengaw, E. A. Essex, and R. Birsa \\ Cooperative Research Centre for Satellite Systems, Physics Department, La Trobe University, Vic 3086, Australia
}

Received: 29 July 2003 - Revised: 19 January 2004 - Accepted: 8 April 2004 - Published: 7 September 2004

\begin{abstract}
The ionospheric storm evolution process was monitored during the 22 September 1999 magnetic storm over the Australian eastern region, through measurements of the ionospheric Total Electron Content (TEC) from seven Global Positioning Systems (GPS) stations. The spatial and temporal variations of the ionosphere were analysed as a time series of TEC maps. Results of our analysis show that the main ionospheric effect of the storm under consideration are: the long lasting negative storm effect during a magnetic storm at mid-latitude regions; the strong, positive disturbances during the storm's main phase at auroral latitude regions; the effects of storm-induced equatorward directed wind causing a positive disturbance at high and mid-latitude stations with appropriate time shift between higher and lower latitudes; daytime poleward movement of depleted plasma that causes temporary suppression of the equatorial anomaly during the start of the storm recovery phase; and prompt penetration of eastward electric fields to ionospheric altitudes and the production of nearly simultaneous TEC enhancement at all latitudes. In general, we found dominant negative disturbance over mid and high latitudes and positive disturbance at low latitudes. A comparison of storm-time behaviour of TEC determined from GPS satellites, and $f_{o} \mathrm{~F}_{2}$ derived from ionosondes at a range of latitudes, showed reasonable agreement between the two independent measurements.
\end{abstract}

Key words. Ionosphere (ionospheric disturbances; equatorial ionosphere; mid-latitude ionosphere)

\section{Introduction}

Notwithstanding the fact that ionospheric storms have been the subject of scientific enquiry for several decades now, storm effects have not yet been fully explained, especially in the Southern Hemisphere, where less research has been undertaken. The most significant remaining problems, as well as recent advances in the study of the ionospheric storms,

Correspondence to: E. Yizengaw

(ekassie@igpp.ucla.edu) have been well documented elsewhere (e.g. Pröllss, 1991; Buonsanto, 1999; Danilov and Lastovicka, 2001 and references therein).

During magnetic storms, the disturbed solar wind compresses the Earth's magnetosphere, and intense electric fields are mapped along geomagnetic field lines to the high latitudes (Fejer, 2002 and references therein), causing significant joule heating to the ionosphere (Prölls, 1997). At times these electric fields penetrate to low latitudes, and at high latitudes they produce a rapid convection of plasma which also drives the neutral winds via collisions. At the same time the auroral oval expands to lower latitudes, and the associated energetic particles precipitate to the lower thermosphere and below, increasing ionospheric conductivity. Intense field-aligned electric currents couple the high latitude ionosphere with the magnetosphere, and the enhanced energy input to the ionosphere causes considerable heating of the ionized and neutral gases. The resulting expansion of the thermosphere produces gradients in pressure, which drive strong neutral winds. The disturbed thermospheric circulation alters the neutral composition, and moves the plasma up and down along the magnetic field lines, changing the rate of production and recombination of the ionized species.

The statistical picture of ionospheric storms was described in detail in earlier studies (e.g. Rodger et al., 1989; Szuszczewicz et al., 1998; Danilov, 2001). Prölls et al (1991) even made an attempt to classify the possible causes of positive and negative ionospheric storm effects using the data from ground-based ionosondes. The objective of this study is to ascertain the nature of storm-related variations in one of the main ionospheric parameters, TEC, at different latitudes in the Southern Hemisphere during all stages of the major magnetic storm on 22 September 1999.

\section{Data analysis}

TEC can be derived from transionospheric GPS signals recorded at ground-based GPS receivers (Klobuchar, 1991, 1996; Breed et al., 1997; Makela and Kelley, 2001). Methods 
of TEC calculation from GPS observations have been described in detail in several papers (Sardón et al., 1994, Breed et al., 1996 and the reference therein). More specifically, Horvath and Essex (2003b) have clearly outlined the algorithm that has been used in this paper, which uses the methods described by Sardón et al. (1994). Here we give a brief description of the procedure.

The total electron content along the GPS raypath from a satellite to a receiver is known as slant TEC (STEC). The STEC can be obtained from the difference between the pseudoranges $\left(\mathrm{P}_{1}\right.$ and $\left.\mathrm{P}_{2}\right)$, and the difference between the phases $\left(\mathrm{L}_{1}\right.$ and $\left.\mathrm{L}_{2}\right)$ of the two GPS signals (Klobuchar, 1996; Horvath and Essex, 2003b). The relevant equations are:

$S T E C_{C o}=\left[\left(\frac{f_{2}^{2}}{f_{1}^{2}-f_{2}^{2}}\right) \frac{2 f_{1}^{2}}{K}\right]\left(P_{2}-P_{1}\right)$

$S T E C_{P h}=\left[\left(\frac{f_{2}^{2}}{f_{1}^{2}-f_{2}^{2}}\right) \frac{2 f_{1}^{2}}{K}\right]\left(L_{1} \lambda_{1}-L_{2} \lambda_{2}\right)$,

where $f_{1}$ and $f_{2}$ are GPS signal frequencies and are equal to $1.57542 \mathrm{GHz}$ and $1.2276 \mathrm{GHz}$, respectively, $K=80.62 \mathrm{~m}^{3} \mathrm{~s}^{-2}$ is a constant that relates plasma frequency to electron density, $\lambda_{1} \lambda_{2}$ are the wavelengths corresponding to $f_{1}$ and $f_{2}$. The STEC from differential phase $\left(\right.$ STEC $\left._{P h}\right)$ is less affected by multipath effects (Klobuchar, 1996; Jakowski et al., 1996), and thus it provides smoother and high precision measurements of STEC. However, because of the $2 \pi$ ambiguity in phase measurements, the absolute value of STEC cannot be determined. Hence, there is an "offset" and so the TEC determined from the phase measurements is called the relative TEC and is referenced to an arbitrary zero reference value at the start of the observation of satellite pass. On the other hand, even though it is highly sensitive to the multipath effect, the STEC from differential pseudoranges $\left(\right.$ STEC $_{C o}$ ) does provide absolute values of TEC. Therefore, to retain the relative accuracy of the phase path measurements, the $\mathrm{STEC}_{P h}$ values for a given satellite pass are fitted to the level of the STEC $_{C o}$ measurements, thereby determining the true baseline value for the differential phase related TEC, STEC $_{P h}$ such that

$S T E C=S T E C_{P h}+B_{r s}$.

If $\mathrm{N}$ measurements are obtained during a satellite pass, $B_{r s}$ is computed as the rms difference between STEC $_{C o}$ and STEC $_{P h}$ as follow.

$B_{r s}=\sqrt{\frac{\sum_{i=1}^{N}\left(S T E C_{\mathrm{Coi}}-S T E C_{\mathrm{Phi}}\right)^{2}}{N}}$,

where $\mathrm{i}=1,2,3,-\mathrm{N}$.

To compare electron content for paths with different elevation angles, the slant electron contents must be transformed into equivalent vertical contents. This conversion, however, is complicated by at least two major factors: the shape of the electron density vertical profile and horizontal gradients in TEC. To overcome the first problem, it is customary to assume the Earth's ionosphere as a thin-shell model at a fixed height $\left(h_{s p}\right)$ in the range 350-400 km (Klobuchar, 1996; Breed, 1996). The choice of a particular height of the thin shell is not particularly critical, except under a few conditions, such as: (1) in the evening near the magnetic equator where vertical drift raises the peak of the $F_{2}$ layer to heights of the order of $600 \mathrm{~km}$ and (2) in winter nights in the middle and low latitudes when the $\mathrm{F}_{2}$ layer decays and the protonosphere content above about $2000 \mathrm{~km}$ is comparable with the ionospheric content. Titheridge (1972) made extensive calculations with theoretical electron density profiles and showed that a global average height of $420 \mathrm{~km}$ is appropriate for oblique to vertical conversion. As Breed (1996) clearly demonstrated, using different thin-shell heights for different local times and seasons of the year, the magnitude of the error arising from an incorrect choice of median height are insignificant for measurements at an elevation angle greater than $\sim 15^{\circ}$. He found that $400 \mathrm{~km}$ is an appropriate height for the oblique to vertical conversion. Even during the worst conditions mentioned above, its effect is insignificant for measurements at higher elevation. The horizontal TEC gradients are also insignificant at higher elevation angles, and thus for this paper all measurements below $20^{\circ}$ elevation angle have been discarded.

For this paper $h_{s p}=400 \mathrm{~km}$ has been used to convert slant TEC to vertical TEC (VTEC) and is, therefore, mathematically given by:

$$
V T E C=\left(S T E C-R_{B}-T_{B}\right)\left(\sqrt{1-\left(\frac{R_{e} \cos \varepsilon}{h_{s p}+R_{e}}\right)^{2}}\right)
$$

where $R_{e}$ is the radius of the Earth, $\varepsilon$ is the elevation angle of the satellite. $R_{B}$ and $T_{B}$, respectively, are corrections for receiver and transmitter (satellite) biases. Breed et al. (1997) have clearly described the methods used here to determine the instrumental (receiver and transmitter) biases. Furthermore, pre-processing of the GPS data is also performed to detect and remove, or correct signal outliers and signal cycle slips.

For this type of measurement, with the sampling rate of $30 \mathrm{~s}$, RMS values as high as 5 TECU were obtained at the equatorial region compared to RMS values less than 2 TECU at the mid- and high-latitude regions. All the plots shown have been obtained by combining vertical TEC observations from all GPS satellites that were operating during the campaign, with a temporal resolution of 15 minutes.

The response of the ionosphere to geomagnetic disturbances is most conveniently described in terms of $\triangle T E C \%$, the percentage deviation of TEC from the quiet time value (Förster and Jakowski, 2000).

$\Delta T E C \%=\frac{\left(T E C_{\text {dist }}-T E C_{\text {quiet }}\right)}{T E C_{\text {quiet }}} \times 100 \%$. 


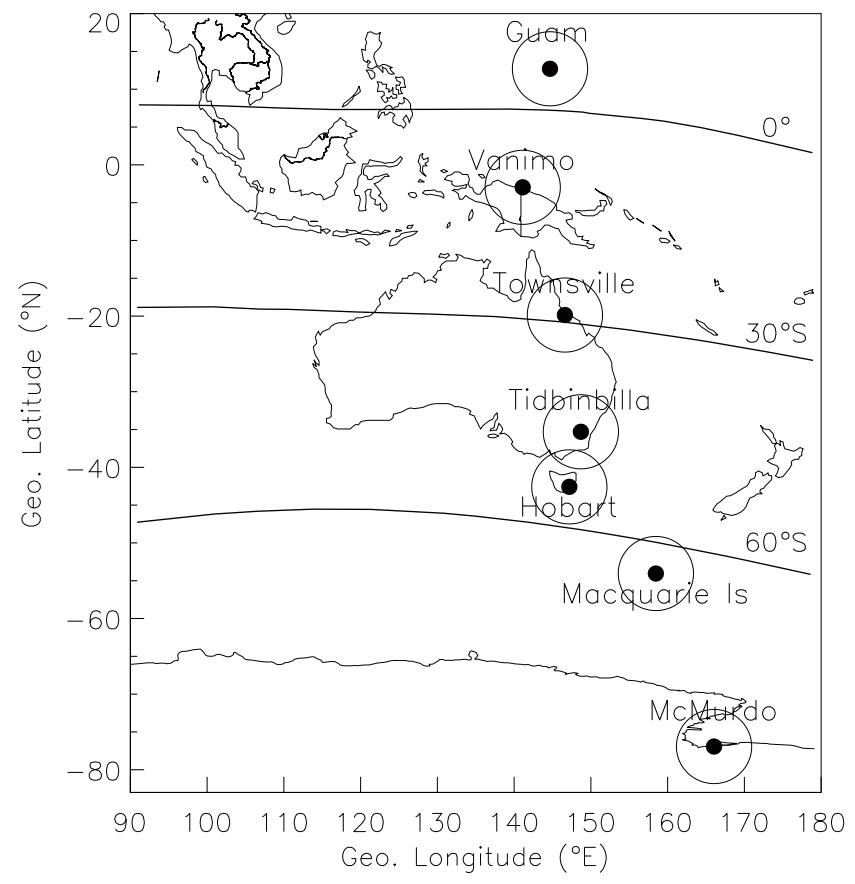

Fig. 1. Geographic maps and field of view $\left(20^{\circ}\right.$ elevation $)$ of the seven GPS receiver stations that provided data for this study. Only the receiver located at Guam evaluates the TEC at latitudes north of magnetic equator. The three horizontal curves depict the geomagnetic latitude axis at $0^{\circ}, 30^{\circ} \mathrm{S}$, and $60^{\circ} \mathrm{S}$, respectively, from top to bottom.

In this case the quiet day values are the TEC values obtained from the combination of six quiet days, with the $K_{p}$ value less than 2 .

\section{Observation}

The ground-based GPS TEC data from the equatorial stations Guam and Vanimo, the equatorial anomaly peak station Townsville, the mid-latitude stations Tidbinbilla and Hobart, the auroral station Macquarie Island, and the cusp station McMurdo are studied in detail for the period of 22-25 September 1999. This latitudinal chain of stations, operated by International GPS Service (IGS), is located close to the $150^{\circ} \mathrm{E}$ meridian as shown in Fig. 1. Both geographic and geomagnetic coordinates of all stations are given in Table 1.

The nature of the September storm is shown in Fig. 2 which presents the most frequently used geomagnetic indices $\left(D_{s t}, A E\right.$ and $\left.K_{p}\right)$ and the GSM z-component of the Interplanetary Magnetic Field (IMF) (taken from Advanced Composition Explorer (ACE) satellite data set). The storm sudden commencement (SSC), indicated by the broken line, occurred on 22 September 1999 at 12:22 UT which is premidnight sector for the $150^{\circ} \mathrm{E}$ meridian sector. A moderate magnetic storm also occurred on 21 September as indicated by $K_{p}$-index reaching $4^{-}$between 12:00 UT Septem-

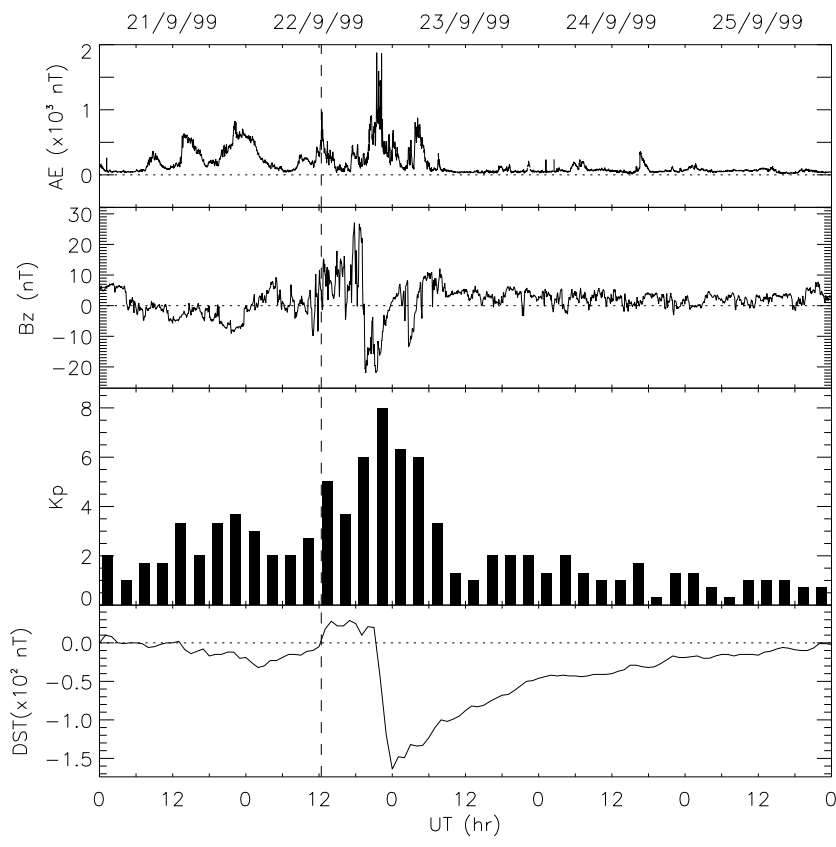

Fig. 2. Variation of geomagnetic indices: $A E$-index, IMF $B_{z}$-component, $D_{s t}$ and $K_{p}$ indices are shown from top to bottom panels, respectively. The vertical broken line depicts the Storm Sudden Commencement (SSC) of the 22 September storm.

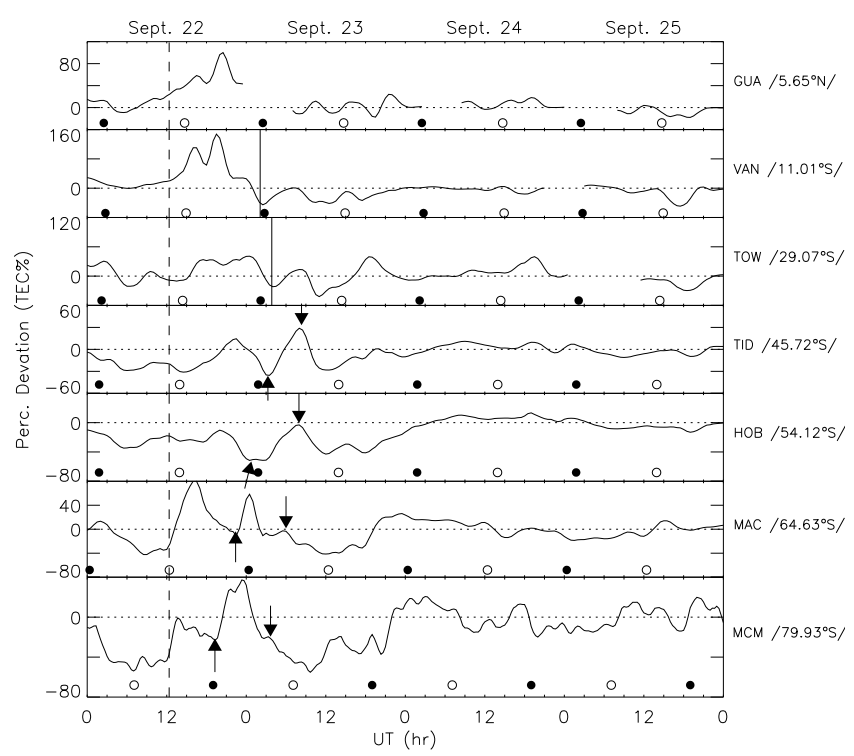

Fig. 3. Temporal profile of percentage deviation of storm time TEC, relative to quiet days (six days average), during 22-25 September at different latitudes. Vertical broken line indicates SSC. Open and solid circles on the time axis correspond to local midnight and noon, respectively.

ber 21:00 and 02:00 UT on 22 September where after it remained under $3^{-}$until the SSC.

The ground based GPS TEC obtained from the chain of stations is shown in Figs. 3 and 4, which show, respectively, the diurnal behaviour of $\triangle T E C \%$ and TEC for 22-25 
Table 1. Geographic and geomagnetic coordinates of the chain of IGS stations that provided data for this study. The three letters in bracket refer to the abbreviation of the station names.

\begin{tabular}{lllll}
\hline \multirow{2}{*}{ Stations } & \multicolumn{2}{l}{ Geographic coordinates } & \multicolumn{2}{l}{ Geomagnetic coordinates } \\
& Latitude $\left({ }^{\circ} \mathrm{N}\right)$ & Longitude $\left({ }^{\circ} \mathrm{E}\right)$ & Latitude $\left({ }^{\circ} \mathrm{N}\right)$ & Longitude $\left({ }^{\circ} \mathrm{E}\right)$ \\
\hline Guam (GUA) & 13.59 & 144.87 & 5.65 & -144.69 \\
Vanimo (VAN) & -2.40 & 141.24 & -11.01 & -147.45 \\
Townsville (TOW) & -19.63 & 146.85 & -29.07 & -139.52 \\
Tidbinbilla (TID) & -35.38 & 148.97 & -45.72 & -133.95 \\
Hobart (HOB) & -42.81 & 147.44 & -54.12 & -133.50 \\
Macquarie Island (MAC) & -54.50 & 158.94 & -64.63 & -112.12 \\
McMurdo (MCM) & -77.84 & 166.67 & -79.93 & -33.15 \\
\hline
\end{tabular}

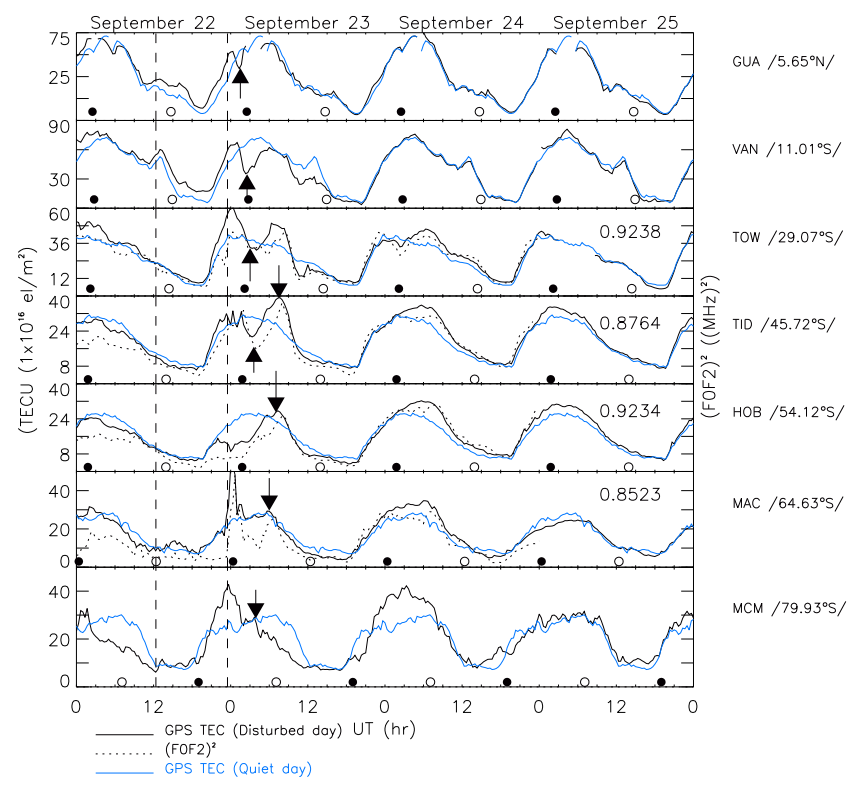

Fig. 4. Diurnal GPS TEC values (solid lines) at the chain of stations and ionosonde $\left(f_{0} F_{2}\right)^{2}$ data (dotted lines) over Townsville, Tidbnbila, Hobart and Macquarie Island. $f_{o} \mathrm{~F}_{2}$ data was not available from the remaining stations to present comparison. Vertical broken lines at the left and right, respectively, depict the SSC time and TEC enhancement peaks that occurred nearly simultaneously $(<1 / 2 \mathrm{~h})$.

September 1999. During the campaign dropouts occasionally occurred in the GPS signals at the equatorial and lower latitude sites, leading to the data gaps in the TEC curves in Figs. 3-5. The three letters and the number at the right side of each panel refer to the abbreviated name of the stations and their corresponding geomagnetic latitudes. The $\mathrm{F}_{2}$ layer critical frequency, $f_{0} F_{2}$ for 22-24 September, obtained from the ionosonde stations at Townsville, Tidbinbilla, Hobart, and Macquarie Island, are also plotted in Fig. 4 (dotted lines) to provide a comparison with the GPS data. On the whole, the good correlation between GPS TEC and $\left(f_{0} F_{2}\right)^{2}$ took place for all stations where $f_{o} \mathrm{~F}_{2}$ data was available. $f_{0} F_{2}$ data was not available from the remaining stations to present comparison. Open and solid circles on the time axis of Fig. 3 and

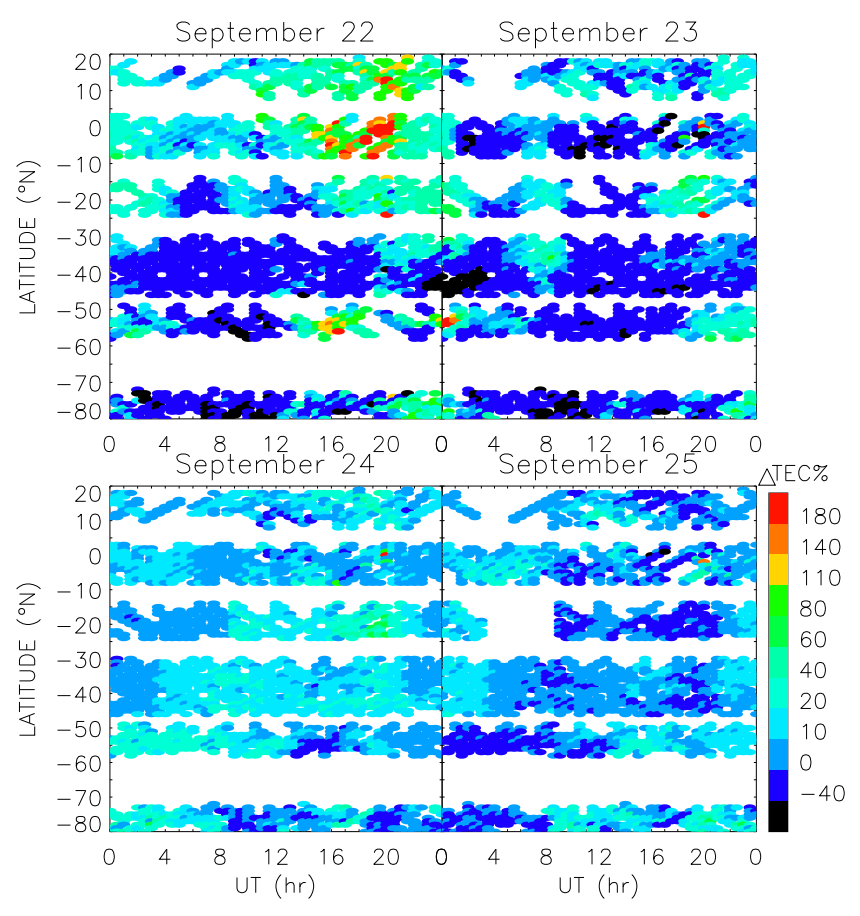

Fig. 5. The latitude-local time $(\mathrm{LT}=\mathrm{UT}+10)$ contour maps of $\triangle T E C \%$ during the first day of the storm (left top), the second day of the storm (right top), the third day of the storm (left bottom) and the fourth day of the storm (right bottom).

4 correspond to local midnight and noon, respectively. The vertical TEC and $f_{0} \mathrm{~F}_{2}$ can be related by a simple mathematical equation (Förster and Jakowski, 2000):

$V T E C=\frac{\tau\left(f_{0} F_{2}\right)^{2}}{806.45}$

where VTEC is given in TEC units, $f_{0} \mathrm{~F}_{2}$ in $\mathrm{MHz}$, and $\tau$ in $\mathrm{km}$. The numbers, shown at the top corners of the middle four panels of Fig. 4, are the correlation coefficients between the TEC and $f_{0} F_{2}$ data obtained for four days. They show that there is a good correlation with correlation coefficients greater than 0.85 at all four stations.

To demonstrate the influence of the magnetic storm on latitudinal gradients and local time behaviour, the longitudinal 
difference of GPS data from different stations are corrected to a common median longitude $\left(150^{\circ} \mathrm{E}\right)$, using a simple relation described by Horvath and Essex (2003b). Hence, $\triangle T E C \%$ and TEC are shown as latitude-local time $(\mathrm{LT}=\mathrm{UT}+10)$ contour plots in Figs. 5 and 6. The station plots in Figs. 3 and 4 are equivalent to horizontal slices in Figs. 5 and 6 which are not extrapolated. The observation results presented in Figs. 3-6 reveal the following outstanding features of the storm event.

A TEC depletion, or negative storm effect, occurred at high- and mid-latitudes before SSC time (prior to 12:22 UT) on 22 September. It persists at high latitudes until SSC time and even extends until about 19:00 UT on the same day at mid-latitudes, as is most obvious in Figs. 3 and 5. However, any pre-storm TEC depletion is insignificant throughout the equatorial region, including equatorial anomaly peak stations.

A similar negative storm effect occurred during the postSSC period at McMurdo between 14:30 and 18:30 UT on 22 September, with a maximum depletion of $\sim 30 \%$ in $\triangle T E C \%$ at 18:30 UT (about local noon). The effect then expands to mid-latitudes, resulting in a moderate ionization depletion $(\sim 5 \%$ in $\triangle T E C \%)$ at Macquarie Island and a deep trough (40-50\% in $\triangle T E C \%)$ at lower mid-latitudes at the times indicated by the upward-pointing arrows in Fig. 3. A similar equatorward expansion of a trough-like structure occurred during nighttime, mainly about local midnight, on 23 September.

A significant daytime ionization depletion at the equatorial station Vanimo occurred between 01:00-03:00 UT, with maximum depletion occurring at 02:00 UT on 23 September (indicated by the vertical line in Fig. 3 and the upward arrow in Fig. 4). It then spreads poleward as evidenced by the minimum in ionization at Townsville at 04:00 UT (indicated by the vertical line in Fig. 3 and by the upward arrow in Fig. 4). The features are also evident in Figs. 5 and 6 which show more clearly the latitudinal and local time boundaries of the features.

Positive storm effects, i.e. ionisation increases, occurred at auroral and equatorial latitudes as evidenced by the TEC enhancements at Macquarie Island and Guam and Vanimo, that occurred just at SSC on 22 September. This positive storm effect increased and reached $\sim 100 \%$ in $\triangle T E C \%$ at Macquarie Island about 16:00 UT before returning to its quiet day level at 21:00 UT on 22 September. Similarly, at the equatorial latitudes, the positive storm effect developed and reached $\sim 160 \%$ in $\triangle T E C \%$ around 20:00 UT on the same day. Ionization at the cusp station McMurdo, however, began to recover from its pre-storm dramatic depletion, but, as shown in Fig. 3, after reaching the quiet day level at 13:30 UT on 22 September, it then decreased.

There is also an ionization enhancement peak that appeared nearly simultaneously at all the stations at 23:30 UT on 22 September. This is evident in Fig. 6 and is indicated in Fig. 4 by the vertical broken line to the right. Although the ionization at Hobart is seriously reduced, i.e. there is a

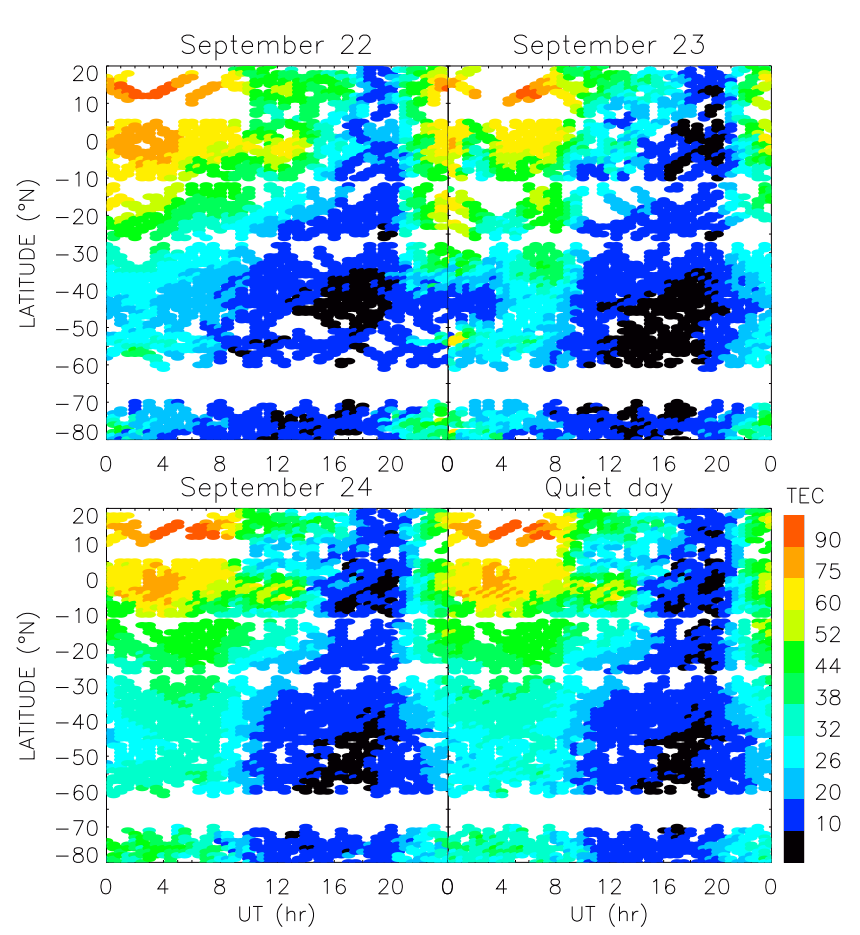

Fig. 6. The latitude-local time (LT=UT+10) contour maps of TEC during quiet days (right bottom), the first day of the storm (left top), the second day of the storm (right top) and the third day of the storm (left bottom).

strong negative storm effect (Fig. 4), it does recover and show a slight enhancement above its previous ionization level.

Significant ionization enhancements at high- and midlatitudes occur after local sunset on 23 September, as indicated by the downward-pointing arrows in Figs. 3 and 4. These enhancements increase as latitude decreases, as shown in Figs. 3-6.

Apart from small-scale TEC fluctuations at the cusp station of McMurdo, there is not much evidence of any storm influence on TEC during the storm recovery phase on 24-25 September.

\section{Discussion}

As shown in Figs. 3 to 6, the severe magnetic storm on 22 September created significant ionization perturbations that were detected in TEC observations obtained by the chain of GPS stations listed in Table 1. Both negative and positive effects occurred during the event.

The TEC depletion at McMurdo between 14:30-18:30 UT on 22 September was followed by the equatorward expansion of this negative effect. According to the current theories (Fuller-Rowell et al., 1997; Buonsanto, 1999 and the reference therein), this could be explained as follows. During geomagnetic storms the cross-polar-cap potential drop increases markedly, leading to an increased input of energy to the region and an expansion of the neutral atmosphere. Such rapid expansion may cause upwelling (i.e. the motion of air 
through constant pressure surfaces), which causes the depletion of the atom-to-molecule ratio as air of different composition is raised to higher altitudes. This change in chemical composition causes increased recombination in the ionosphere and a reduction in ionization concentration. Rapid heating and expansion of the atmosphere at high latitudes results in pressure gradients, which, in turn, modify the global thermospheric circulation, producing enhanced equatorward winds. The storm-induced equatorward winds, in turn, transport the composition changes to middle latitudes, again causing a reduction in the level of ionization. This equatorward expansion is therefore consistent with the steep decreases in ionization, which occur in the daytime and appear later in time as one moves from high- to mid-latitudes (see Figs. 3 and 5). The delay in the occurrence time of a negative $\triangle T E C \%$ between high- and mid-latitudes (indicated by the upward arrows in Fig. 3) is probably due to the propagation delay of the ionospheric/atmospheric disturbance (Jakowski et al., 1999). Indeed, the $\triangle T E C \%$ trough maximized at McMurdo at 18:30 UT on 22 September, while the one at Hobart maximized about $4 \mathrm{~h}$ later. This would correspond to a wind velocity of the order of $200-500 \mathrm{~ms}^{-1}$, which is in agreement with current theories (Prölls, 1997) and other experimental observations (Förster and Jakowski, 2000). Similarly, the prominent pre-storm TEC depletions at high- and mid-latitudes could be related to the moderate storm that occurred on 21 September.

The unusual daytime poleward expansion of depleted TEC at the equatorial and equatorial anomaly peak regions in between 01:00-04:30 UT on 23 September, as shown in Figs. 3-6, has not been reported before. It could be related to the following. Despite the fact that there is energy input of the penetration of the electric field, which can cause joule heating in the ionosphere (Liu et al., 2000), there has been speculation about an additional source of energy at lower latitudes during disturbances. In particular, Noël and Pröllss (1993) suggested that heating by a neutralized ring current could be the possible heat source at equatorial and tropical latitudes. According to the current general understanding, the direction of the atmospheric circulation is generally poleward during the day and equatorward during the night. Moreover, higher energy input to the equatorial latitudes may enhance the daytime poleward circulation, and these enhanced poleward winds can, in turn, move the ionization along the magnetic field lines to lower altitudes where the chemical loss rate is greater (Balan et al., 1991; Pröllss, 1997). However, such enhanced daytime poleward circulation has not previously been supported by experimental observations. The GPS TEC observations of the 22 September severe storm show consistent low-latitude behaviour with that predicted by Balan et al. (1991) and Pröllss (1997). That is a daytime poleward expansion of a region of plasma which depletion occurred on 23 September as indicated by vertical solid lines and upward arrows, respectively, in Figs. 3 and 4. Note that it also caused a temporary suppression of the equatorial anomaly at the start of the storm recovery phase (23 September) (see top right panels in Figs. 5 and 6). This could
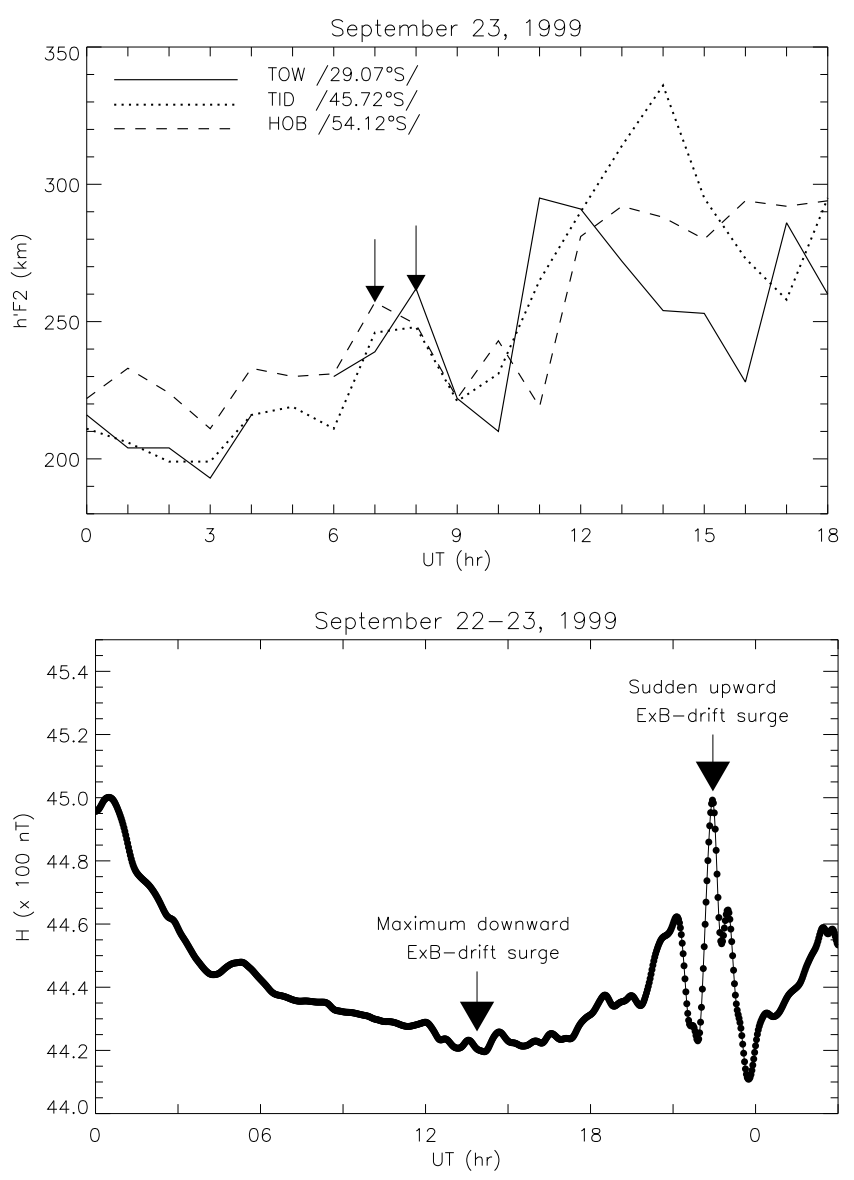

Fig. 7. (a) An hour interval virtual F-region height $\left(h^{\prime} F\right)$ adopted from ionsonde data recorded at the three stations (Townsville, Tidbinbilla, and Hobart) on 23 September. (b) The $\Delta H$ (difference between the horizontal component of the geomagnetic field $(\mathrm{H})$ at the equator and at non-equator regions) obtained from the magnetometer data at Hatizyo $\left(23.46^{\circ} \mathrm{N},-152.18^{\circ} \mathrm{E}\right.$ geomagnetic $)$ and at Guam $\left(4.57^{\circ} \mathrm{N},-145.24^{\circ} \mathrm{E}\right.$ geomagnetic) to estimate vertical $E \times B$-drift.

be related to the downward, lower altitude motion of the ionospheric F-layer. Tan (1982) and Balan and Rao (1984) have shown that enhancements in peak electron density and TEC can occur at equatorial anomaly latitudes only if the F-layer remains at an altitude above about $250 \mathrm{~km}$. Similarly, Fig. 7a, representing the virtual F-layer height $\left(h^{\prime} F\right)$ obtained from ionosonde stations at Townsville, Tidbinbilla, and Hobart, shows that the bottom of the F-layer is depressed down to $190 \mathrm{~km}$ or less around local noon at Townsville and Tidbinbilla. Although this doesn't necessarily mean that the F-layer peak height is less than $250 \mathrm{~km}$, it indicates that the F-layer was relatively low at Townsville at the time of the TEC enhancement and in this respect it is in agreement with the above interpretation.

A significant positive effect at Macquarie Island (up to $100 \%$ or more) during the storm onset time, with a maximum at 16:00 UT on 22 September, is likely due to the energetic particles that precipitate at auroral or sub-auroral latitudes during magnetic disturbances (Jakowski, 1999). 
The Auroral Particle and Imagery plot for this event (available at http://sd-www.jhuapl.edu/Aurora/ovation/ovation $\{\backslash$ - $\}$ display.html) shows that the auroral oval was expanded equatorward and totally covered Macquarie Island during the 22 September storm onset period. Ho et al. (1998) and Jakowski et al. (1999) observed similar ionization increases at the auroral and sub-auroral regions in the Northern Hemisphere during the severe magnetic storm on 10 January 1997. At McMurdo, however, it is suggested that enhanced recombination due to an excessive precipitating particle energy input to the region enhanced the recombination rate (referred above), so that the TEC was depleted by about $30 \%$.

The strong positive storm effect at equatorial stations between 12:00-21:00 UT (during local nighttime), with a maximum enhancement peak ( $\sim 160 \%$ at Vanimo) at 20:00 UT (just before local sunrise), on 22 September, can be explained by an increased downward flow of plasma from the plasmasphere due to strong downward $E \times B$ drift. The horizontal component of the geomagnetic field at the magnetic dip equator reflects the change in the equatorial plasma fountain, and the difference between $H$ at the equator and at a nonequatorial location is a good indicator of the vertical $E \times B$ drift (Horvath and Essex, 2003a). Figure 7b displays the parameter $\Delta H=H_{\text {equator }}-H_{\text {non-equator }}$ where Guam $\left(4.57^{\circ} \mathrm{N}\right.$, $-145.24^{\circ} \mathrm{E}$ geomagnetic) and Hatizyo $\left(23.46^{\circ} \mathrm{N},-152.18^{\circ} \mathrm{E}\right.$ geomagnetic) have been used to determine $H_{\text {equator }}$ and $H_{\text {non-equator }}$, respectively, in the $145^{\circ} \mathrm{E}$ longitude sector.

It can be seen from Figure $7 \mathrm{~b}$ that $\Delta H$ is the lowest between 12:30-17:30 UT (local nighttime in that the zonal electric field is westward) on 22 September. Therefore, this is when we can expect the maximum downward $E \times B$ drift, which is at the same time as the TEC enhancement occurred at the equator.

The TEC enhancements peak that is nearly simultaneous at all stations at 23:30 UT on 22 September (see Figs. 4 and 6) may well be related to electric field penetration to lower latitudes in the ionosphere. Theoretical considerations (Buonsanto, 1999 and references therein) and earlier observations (Jakowski et al., 1999; Basu et al., 2001) show that the zonal electric field of magnetospheric origin may penetrate down to the ionosphere when the IMF turns southward and before the ring current has developed. In the case of the 22 September storm event the IMF turned southward dramatically at 19:30 UT, which is approximately the same time as the TEC enhancement commenced. Moreover, the vertical $E \times B$-drift estimator, $\Delta H$, shows a dramatic peak at 22:30 UT, which is well correlated with the TEC enhancement. This vertical drift is also supported by the ionosonde measurement data. In the first approximation the TEC can be expressed via the F-region peak frequency and the ionospheric slab thickness using a simplified relation given by Breed et al. (1997) and Förster and Jakowski (2000). So, if the slab thickness is not changed at the stations where the ionosonde data was available then the TEC is in proportion to the square of $f_{0} F_{2}$. Indeed the diurnal behaviours of GPS TEC (solid lines) and $\left(f_{0} F_{2}\right)^{2}$ (dotted lines), which is normalised to $1 / 3$, shown in Fig. 4 , indicate that $\left(f_{0} F_{2}\right)^{2}$ is declining whilst TEC maintains significant ionization during the period mentioned above. This indicates that the plasma is drifted to the topside ionosphere since this region of the ionosphere contributes to TEC, whereas $\left(f_{0} F_{2}\right)^{2}$ describes conditions at the F-layer peak which are affected by the eastward electric field mentioned above.

Strong TEC enhancements at McMurdo between 21:00 23:30 UT and at Macquarie Island between 00:00-01:00 UT on 22 and 23 September could result from the equatorward migration of the negative storm effect. Balan et al. (1991) suggested that as the trough moves equatorward from highlatitudes particle precipitation enhances the ionization in the region previously occupied by the trough. Indeed, this is consistent with the steep increase with time of $\triangle T E C \%$ at the two stations mentioned above.

Now consider the post-sunset TEC enhancements observed at high- and mid-latitudes on 23 September, as indicated by the downward arrows in Figs. 3 and 4. There is a clear explanation for this event. Storm associated energy input into high latitudes (referred above) induces meridional equatorward winds through atmospheric heating. The storm induced meridional winds, in turn, drive the plasma along magnetic field lines to higher altitudes where the plasma loss rate is lower. This plasma uplifting is more effective at mid-latitudes where the geomagnetic inclination is close to $45^{\circ}$ (Buonsanto, 1999; Jakowski et al., 1999 and references therein). Indeed, this is quite consistent with our observations presented in Figs. 3-6, which show a positive effect greatest at Tidbinbilla. Furthermore, the uplifting effect, which first occurred at McMurdo at 03:00 UT on 23 September, occurred at Tidbinbilla about $4 \mathrm{~h}$ later. This corresponds to a propagation velocity of the order of 400 $600 \mathrm{~ms}^{-1}$, which is in agreement with current theories (e.g. Pröllss, 1997) and earlier observations (e.g. Jakowski et al., 1999). The virtual F-layer height parameter, $h^{\prime} F$, measured by ionosondes, also shows the same plasma uplifting delay in time at lower latitudes, as indicated by the vertical arrows in Fig. 7 a.

Although it has been extensively studied and well documented (e.g. Fuller-Rowell et al., 1997; Buonsanto, 1999; Jakowski et al., 1999 and the reference therein), it is worth mentioning the difference between the TEC enhancement mechanisms due to storm-induced meridional winds and intensified zonal electric field. The important role of these two mechanisms for explaining the positive storm effect is generally accepted. However, there is a big difference between them as evidenced by ground-based observations. The ionization enhancement due to the intensified zonal electric fields was revealed nearly simultaneously at different latitudes, whereas there is a significant time gap between higher and lower latitudes in the case of the meridional wind uplifting effect. This time gap is believed to be due to the propagation delay of the wind (e.g. Pröllss, 1997, Fuller-Rowell et al., 1997).

Although the recovery phase of the magnetic storm continued through the 24 and 25 September, there is little evidence in Figs. 3-6 of any storm effect in the ionosphere apart 
from relatively small-scale fluctuations in the cusp region, as shown by the observations at McMurdo. This indicates that ionospheric processes have returned to normal after almost two days of quite severe change when the ionization budget was not controlled by the usual local time variations in production, loss and transport, but rather it was controlled and governed by perturbations directly associated with magnetospheric storm phenomena.

\section{Conclusion}

The analysis of the variation of TEC obtained from a latitudinal chain of GPS stations located near the $150^{\circ} \mathrm{E}$ meridian has identified the following overall effects:

- after the SSC, during the initial part of the storm main phase, a region of depleted plasma (negative storm effect) occurs at high latitudes which is then transported to mid-latitudes;

- also during the storm main phase a positive storm effect occurs at auroral and equatorial latitudes;

- storm-induced meridional winds blowing equatorward cause a steep ionization enhancement with time at highand mid-latitudes;

- penetration of magnetospheric origin electric fields to the altitude of ionosphere cause nearly simultaneous TEC increases at all latitudes;

- daytime poleward expansion of depleted ionization forms a belt of depleted ionization which causes a temporary suppression of the equatorial anomaly during the start of the storm recovery phase.

The result pointed out in the last point has not been reported before, and can be considered as the main contribution of this paper to current community knowledge on ionospheric storm effects.

Acknowledgements. The authors would like to thank P. Wilkinson of IPS Radio and Space Services for providing the Ionosonde data, Geoscience Australia National Mapping Division (formerly Australian Surveying and Land Information Group (AUSLIG)) and IGS for the GPS data. This work has been supported by the CRC for Satellite Systems project.

Topical Editor M. Lester thanks A. Krankowski and another referee for their help in evaluating this paper.

\section{References}

Basu, S., Basu, S., Valladares, C. E., Yeh, H. C.,Su, S. Y., Mackenzie, E., Sultan, P. J., Aarons, J., Rich, F. J., Doherty, P., Groves, K. M., and Bullett, T. W.: Ionospheric effects of major magnetic storms during the international space weather period of September and October 1999: GPS observations, VHF/UHF scintillations, and in situ density structures at middle and equatorial latitudes. J. Geophys. Res., 106, 30 389-30 413, 2001.
Balan, N., Bailey, G. J., and Nair, R. B.: Solar and magnetic activity effects on the latitudinal variations of nighttime TEC enhancement. Ann. Geophysicae, 9, 60-69, 1991.

Balan, N. and Rao, P. B.: Relationship between night-time total electron content enhancements and VHF scintillations at the equator. J. Geophys. Res., 89, 9009-9013, 1984.

Breed, A. M: Investigation of the ionosphere over Australia using satellite transmissions. Ph. D. thesis, School of Applied Physics, University of South Australia, 1996.

Breed, A. M., Goodwin, G. L., Vandenberg, A-M., Essex, E. A., Lynn, K. J. W., and Silby, J. H.: Ionospheric total electron content and slab thickness determination in Australia. Radio Sci., 32, 4, 1635-1643, 1997.

Buonsanto, M. J.: Ionospheric storms-a review. Space Sci. Rev., 88, 563-601, 1999.

Danilov, A. D. and Lastovicka, J.: Effects of geomagnetic storms on the ionosphere and atmosphere. Int. J. Geomag. Aeronomy, 2, 209-224, 2001.

Danilov, A. D.: F2-region response to geomagnetic disturbances. J. Atmos. Terr. Phys., 63, 441-449, 2001.

Fejer, B. G.: Low latitude storm time ionospheric electrodynamics. J. Atmos. Terr. Phys., 64, 1401-1408, 2002.

Fuller-Rowell, T. J., Codrescu, M. V., Roble, R. G., and Richmond, A. D.: How does the thermosphere and ionosphere react to a geomagnetic storm? In B.T. Tsurutani, W. D. Gonzales, Y. Kamide and J. K. Arballo (ed.), Magnetic Storms, Geophysical Monography 98, American Geophysical Union, Washington, D.C., 1997.

Förster, M. and Jakowski, N.: Geomagnetic storm effects on the topside ionosphere and plasmasphere: a compact tutorial and new results. Surveys in Geophysics, 21, 47-87, 2000.

Ho, C. M., Mannucci, A. J., Lindqwister, U. J., Pi, X., Tsurutani, B. T., Sparks, L., Iijima, B. A, Wilson, B. D., Harris, I. and Reyes, M. J.: Global ionospheric TEC variations during 10 January, 1997 storm. Geophys. Res. Lett., 25, 2589-2592, 1998.

Horvath, I. and Essex, E. A.: Vertical $\mathrm{E} \times \mathrm{B}$ drift velocity variations and associated low- latitude ionospheric irregularities investigated with the TOPEX and GPS satellite data. Ann. Geophys., 21, 1017-1030, 2003a.

Horvath, I. and Essex, E. A.: The southern-hemisphere mid-latitude day-time and nighttime trough at low-sunspot numbers. J. Atmos. Terr. Phys., 65, 917-940, 2003b.

Jakowski, N., Sardon, E., Engler, E., Jungstand, A., and Klähn, D.: Relationships between GPS-signal propagation errors and EISCAT observations. Ann. Geophys., 14, 1429-1436, 1996.

Jakowski, N., Schluter, S., and Sardon, E.: Total electron content of the ionosphere during the geomagnetic storm on 10 January 1997. J. Atmos. Terr. Phys., 61, 299-307, 1999.

Klobuchar, J. A.: Ionospheric effects on GPS. GPS World, 48-51, 1991.

Klobuchar, J. A.: Ionospheric effects on GPS. In: Parkinson, B.W. and J.J. Spilker (Ed.), Global Positioning System: Theory and application Vol. 1. American Institute of Aeronautics and Astronautics INC., 1996.

Liu, C., Schlegel, K., and Ma, S. Y.: Combined ESR and EISCAT observations of the dayside polar cap and auroral oval during the 15 May 1997 storm. Ann. Geophys., 18, 1067-1072, 2000.

Makela, J. J. and Kelley, M. C.: GPS normalization and preliminary modelling results of total electron content during a midlatitude space weather event. Radio Sci., 36, 351-361, 2001.

Noël, N. and Prölls, G. W.: Heating and radiation production by neutralized ring current particles. J. Geophys. Res., 98, $17317-$ $17325,1993$. 
Prölls, G. W., Brace, L. H., Mayer, H. G., Carignan, G. R., Killeen, T. L., and Klobuchar,J. A.: Ionospheric storm effects at subauroral latitude: A case study. J. Geophys. Res., 96, 1275-1288, 1991.

Prölls, G. W.: Magnetic storm associated perturbations of the upper atmosphere. In B.T. Tsurutani, W. D. Gonzales, Y. Kamide and J. K. Arballo (eds), Magnetic Storms, Geophysical Monography 98, American Geophysical Union, Washington, D.C., 1997.

Rodger, A. S., Wrenn, G. L., and Rishbeth, H.: Geomagnetic storms in the Antarctic F-region. II. Physical interpretation. J. Atmos. Terr. Phys., 51, 851-866, 1989.

Sardón, E., Rius, A., and Zarraoa, N.: Estimation of the receiver differential biases and the ionospheric total electron content from Global Positioning System observations. Radio Sci., 29, 577586, 1994.
Szuszczewicz, E. P., Lester, M., Wilkinson, P., Blanchard, P., Abdu, M., Hanbaba, R., Igarashi, K., Pulinets, S., and Reddy, B. M.: A comparative study of global ionospheric response to intense magnetic storm conditions. J. Geophys. Res., 103, $11665-11684$, 1998.

Tan, A.: On the nighttime increase of $\mathrm{N}_{m} \mathrm{~F}_{2}$ at Jicamarca on 2-3 February 1965. J. Atmos. Terr. Phys., 44, 377-380, 1982.

Titheridge, J. E.: The total electron content of the southern midlatitude ionosphere, 1965-1971. Journal of Atmospheric and Terrestrial Physics 35, 981-1001, 1972. 